\title{
Field Oriented Control of Doubly Fed Induction Motor using Speed Sliding Mode Controller
}

\author{
SAID MAHFOUD ${ }^{1 *}$, AZIZ DEROUICH ${ }^{1}$, NAJIB EL OUANJLI ${ }^{1}$, TAOUSSI MOHAMMED $^{1}$, \\ AHMED HANAFI ${ }^{1}$ \\ ${ }^{1}$ Industrial Technologies and Services Laboratory, Higher School of Technology, \\ Sidi Mohamed Ben Abdellah University \\ Fez, Morocco \\ said.mahfoud@usmba.ac.ma
}

\begin{abstract}
This article presents a modelling and control of the Doubly Fed Induction Motor (DFIM), associated with two inverters controlled through the Pulse Width Modulation technique (PWM), the control of the DFIM is carried out by the approach of Rotor Flux Oriented Control (RFOC) according to the direct axis. In this approach, regulation is done by classic PI regulators, the latter having undesirable overruns and static errors in non-linear systems, for that the introduction of the control by sliding mode in place of the classic PI speed regulator, that is in the form of a control law based on this type of controller since it is invariant to the non-linearity of the system and precise, stable, simple and has a good response time, in order to validate the objectives of improving the DFIM behaviour in front of the reference parameters, such as the speed and the torque imposed on the machine. The results of the proposed approach are validated by its implementation on the Matlab/Simulink environment.
\end{abstract}

Keywords. DFIM, RFOC, PWM, SMC, Matlab/Simulink.

\section{Introduction}

Nowadays, several works have been directed towards the study of the doubly fed induction motor, this latter and thanks to the development of static converters and the appearance of modern control techniques presents an ideal solution for high power drives and variable speed, the association of DFIM with static converters makes it possible to offer different control strategies, especially with the configuration on which this machine is controlled through two voltage inverters connected reciprocally to the stator and rotor windings, since it has several advantages by comparison to other configurations, such as joule losses at the inverters, it also offers a speed variation range up to twice the nominal speed [1][2].

The control of the DFIM is a delicate operation because of the coupling between their different variables unlike a DC machine with independent excitation, which has the simplicity advantage of its control, where there is a natural decoupling between the flux and 
the couple, it is the idea of the appearance of the vector control technique with flux orientation, this technique is proposed in 1973 by Blaschke and Hasse [3][4].

In the field of control, several techniques have been established to ensure the desired adjustment such as the regulation technique by PI or PID regulators which have advantages in linear systems, its applications will be ineffective especially with non-linear systems which can lead to poor robustness and significant overshoots when these parameters vary [5], for this we must use control laws insensitive to parameter variations and non-linearity, the advantages of sliding mode control (SMC) are important and multiple such as precision, stability, simplicity of implementation [6].

The contribution in this work consists in applying the control law by SMC on the speed loop to improve the behaviour of the DFIM in the permanent and transient regime, and to guarantee the best performances of the machine especially with the variations of the reference parameters.

The organization of the article will be as follows: section 1, make a description of the overall system, section 2, Establish the modelling of DFIM, section 3, Describe and establish the modelling of rotor flux oriented control (RFOC), section 4, calculate and determine the parameters of stator and rotor currents regulators and rotor fluxes, section 5 , control the speed by sliding mode, section 6 , Simulate and interpret the simulation results.

\section{Description of the system and modeling of the DFIM}

\subsection{Description of the system}

The system is composed of an uncontrolled rectifier connected with the DC bus in the form of an RLC circuit to reduce the ripples of the rectified voltage and a voltage inverter with which we can control the DFIM via the PWM module, Figure (1) shows the overall system to be studied.

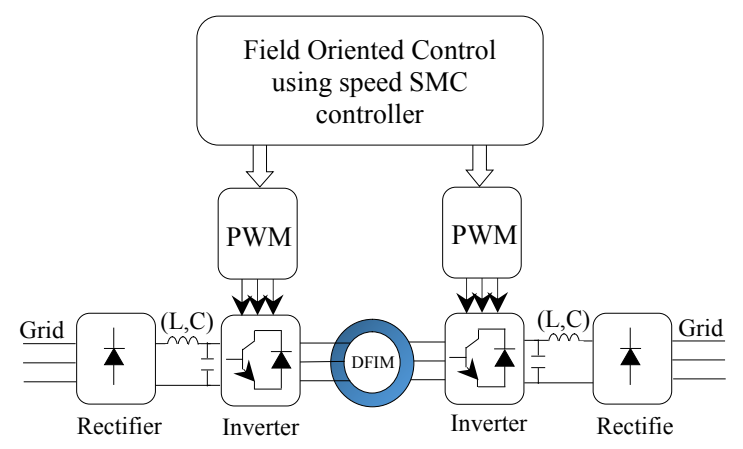

Fig. 1. Global system model

\subsection{Modelling of the DFIM}

The mathematical model of DFIM after the application of the Park transformation to the electrical equations of DFIM in the frame of reference related to the rotating field, allows us to arrive at the following system of electrical equations, taking into account the simplifying hypotheses [5][6]. 
- Electric expressions:

$\left\{\begin{array}{l}v_{s d}=R_{s} \cdot i_{s d}+\frac{d \psi_{s d}}{d t}-\omega_{s} \cdot \psi_{s q} \\ v_{s q}=R_{s} \cdot i_{s q}+\frac{d \psi_{s q}}{d t}+\omega_{s} \cdot \psi_{s d} \\ v_{r d}=R_{r} \cdot i_{r d}+\frac{d \psi_{r d}}{d t}-\omega_{r} \cdot \psi_{r q} \\ v_{r q}=R_{r} \cdot i_{r q}+\frac{d \psi_{r q}}{d t}+\omega_{r} \cdot \psi_{r d}\end{array}\right.$

- Magnetic expressions:

$\left\{\begin{array}{l}\psi_{s d}=L_{s} i_{s d}+M \cdot i_{r d} \\ \psi_{s q}=L_{s} i_{s q}+M \cdot i_{r q} \\ \psi_{r d}=L_{r} i_{r d}+M \cdot i_{s d} \\ \psi_{r q}=L_{r} i_{r q}+M \cdot i_{s q}\end{array}\right.$

- Torque and speed expressions:

$$
\left\{\begin{array}{c}
T_{e m}=p \cdot\left(\psi_{s d} i_{s q}-\psi_{s q} i_{s d}\right) \\
T_{e m}=T_{r}+f \Omega+J \frac{d \Omega}{d t}
\end{array}\right.
$$

\section{Control of the Doubly fed induction motor}

\subsection{Rotor flux oriented control}

The principle of flux oriented control (FOC) consists of orienting the flux in such a way as to bring the behavior of the DFIM similar to that of the DC machine with separate excitation in order to have control of the flux and the torque separately performing decoupling [8][9].

In this study we have chosen to orient the rotor flux according to the direct axis of the referential for this we will have:

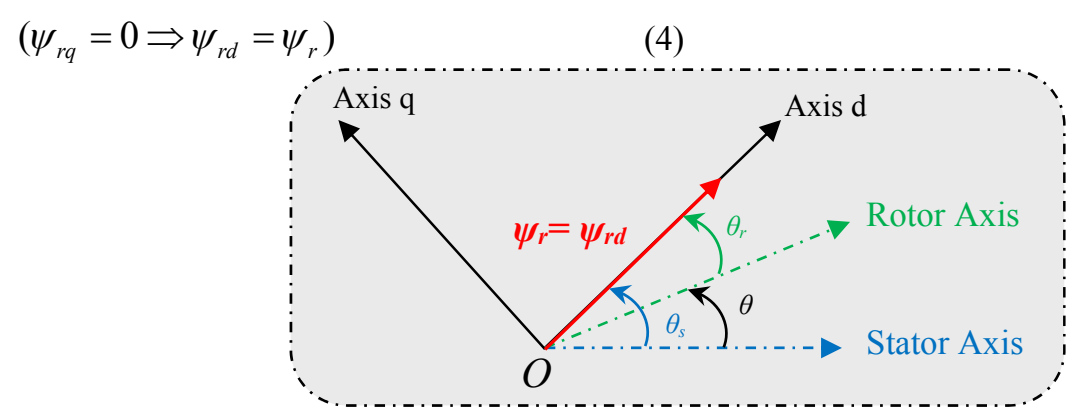

Fig. 2. Principle of the orientation of the rotor flux

Let's apply the law of orientation on the equations of the mathematical model in the plan dq we will have: 


$$
\left\{\begin{array}{l}
\psi_{r d}=\psi_{r}=L_{r} i_{r d}+M . i_{s d} \\
\psi_{r q}=0=L_{r} i_{r q}+M . i_{s q} \\
T_{e m}=-p \cdot \psi_{r d} \cdot i_{r q}
\end{array}\right.
$$

Which gives:

$$
\left\{\begin{array}{l}
i_{s q}=-\frac{L_{r}}{M} i_{r q} \\
i_{r q}=-\frac{M}{L_{r}} i_{s q}
\end{array}\right.
$$

To guarantee a unit power factor just impose [10].

$i_{r d}=0$

From expressions (5), (6) and (7) we can establish the expressions of the reference currents that can be associated with them in the following table:

TABLE I. TABLE OF REFERENCES

\begin{tabular}{|c|c|}
\hline Currents of references & Objectives \\
\hline$\psi_{r q}=0$ & $i_{s q}^{r e f}=-\frac{L_{r}}{P M \psi_{r d}^{r e f}} T_{e m}^{r e f}$ \\
\hline$\psi_{r d}=\psi_{r}$ & $i_{s d}^{r e f}=\frac{L_{r}}{M} \psi_{r d}^{r e f}$ \\
\hline$T_{e m}=T_{e m}^{r e f}$ & $i_{s q}^{r e f}=-\frac{1}{P \psi_{r d}^{r e f}} T_{e m}^{r e f}$ \\
\hline $\operatorname{Cos} \varphi=0$ & $i_{r d}^{r e f}=0$ \\
\hline
\end{tabular}

To meet the theoretical objectives on which the vector control is based, our study is used to make a comparison between the reference parameters of the control with that of the DFIM to extract the error in each parameter in order to control and put it in zero which eliminates the static error with a conservation of the system stability, thus to having a response time rather fast the maximum possible which ensures the decoupling between the flux and the couple.

There are three methods which make it possible to ensure the decoupling between the couple and the flux such as the method of LECOCQ, RAMUZ and GHOSN, each method has its own characteristics but that of LECOCQ is widely used in practice because of their technical performances and their simplicity of implementation [10][11][12].

The principle of this method allows to add compensation terms which leads to new transforms as follows [10][13]: 


$$
\left\{\begin{array}{l}
v_{C s d}=v_{s d}-\frac{M}{L_{r}} \cdot v_{r d} \\
v_{C s q}=v_{s q}-\frac{M}{L_{r}} \cdot v_{r q} \\
v_{C r d}=v_{r d}-\frac{M}{L_{s}} \cdot v_{s d} \\
v_{C r q}=v_{r q}-\frac{M}{L_{s}} \cdot v_{s q}
\end{array}\right.
$$

Based on the expressions (1), (8) and (9) we will have:

$$
\left\{\begin{array}{l}
v_{c s d}=R_{s} \cdot i_{s d}+\sigma L_{s} \frac{d i_{s d}}{d t}-R_{r} \frac{M}{L_{s}} \cdot i_{r d}-\psi_{s q} \cdot \omega_{s}+\frac{M}{L_{r}} \cdot \psi_{r q} \cdot\left(\omega_{s}-\omega\right) \\
v_{c s q}=R_{s} \cdot i_{s q}+\sigma L_{s} \frac{d i_{s q}}{d t}-R_{r} \frac{M}{L_{r}} i_{r q}+\psi_{s d} \cdot \omega_{s}-\frac{M}{L_{r}} \cdot \psi_{r d} \cdot\left(\omega_{s}-\omega\right) \\
v_{C r d}=R_{r} \cdot i_{r d}+\sigma L_{r} \frac{d i_{r d}}{d t}-R_{s} \frac{M}{L_{s}} \cdot i_{s d}-\psi_{r q} \cdot\left(\omega_{s}-\omega\right)+\frac{M}{L_{s}} \cdot \psi_{s q} \cdot \omega_{s} \\
v_{c r q}=R_{r} \cdot i_{r q}+\sigma L_{r} \frac{d i_{r q}}{d t}-R_{s} \frac{M}{L_{s}} \cdot i_{s q}+\psi_{r d} \cdot\left(\omega_{s}-\omega\right)-\frac{M}{L_{s}} \cdot \psi_{s d} \cdot \omega_{s}
\end{array}\right.
$$

So:

$$
\left\{\begin{array}{l}
v_{c s d}=v_{c s d c}+v_{c s d c 1} \\
v_{c s q}=v_{c s q c}+v_{c s q c 1} \\
v_{c r d}=v_{c r d c}+v_{c r d c 1} \\
v_{c r q}=v_{c r q c}+v_{c r q c 1}
\end{array}\right.
$$

With:

$$
\left\{\begin{array}{l}
v_{C s d c}=R_{s} \cdot i_{s d}+\sigma L_{s} \frac{d i_{s d}}{d t} \\
v_{C s q c}=R_{s} \cdot i_{s q}+\sigma L_{s} \frac{d i_{s q}}{d t} \\
v_{C r d c}=R_{r} \cdot i_{r d}+\sigma L_{r} \frac{d i_{r d}}{d t} \\
v_{C r q c}=R_{r} \cdot i_{r q}+\sigma L_{r} \frac{d i_{r q}}{d t}
\end{array}\right.
$$

Where $v_{c s d c l}, v_{c s q c 1}, v_{c r d c l}$ and $v_{c r q c l}$ are considered as compensation terms, which gives the same transfer function between the currents and voltages of the same axis to the stator and for the rotor.

$$
\left\{\begin{array}{l}
\frac{i_{s d}(s)}{v_{C s d c}(s)}=\frac{i_{s q}(s)}{v_{C s q c}(s)}=\frac{1}{R_{s}+\sigma L_{s} \cdot s} \\
\frac{i_{s d}(s)}{v_{C r d c}(s)}=\frac{i_{r q}(s)}{v_{C r q c}(s)}=\frac{1}{R_{r}+\sigma L_{r} . s}
\end{array}\right.
$$

The regulator diagram linked to the stator and rotor currents is illustrated by the following figure (3). 


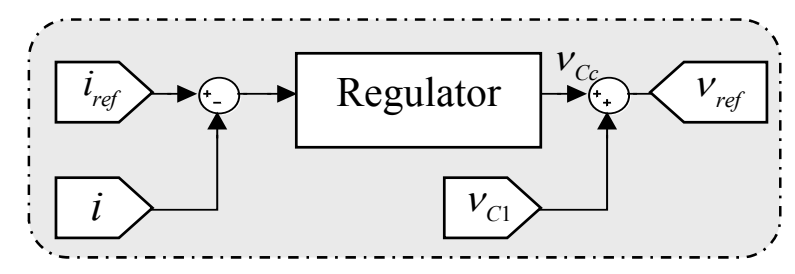

Fig. 3. Scheme of regulator by the LECOCQ method

\subsubsection{Regulation of stator and rotor currents}

The parameters of the stator and rotor currents regulators are calculated in the same way, the block scheme of the stator and rotor currents regulation chain is represented in figure (4)

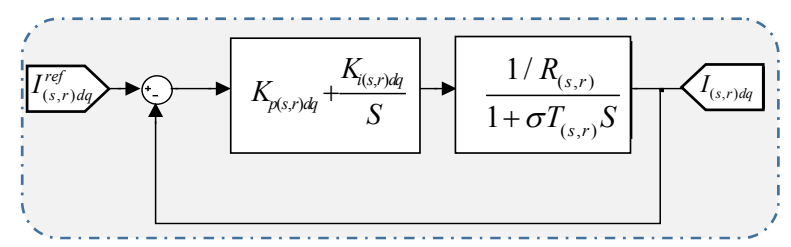

Fig. 4. scheme of stator and rotor currents regulator

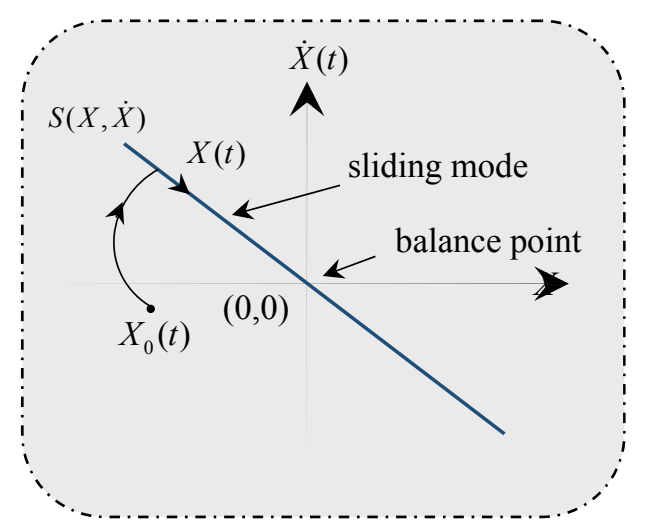

Fig. 6. Operating mode in the phase plane

The design of the sliding mode control takes into account the problems of stability and good performance in a systematic way in its approach, which is mainly carried out in three main steps complementary to each other, defined by [14][15]:

- The choice of sliding surface.

- The definition of the conditions of existence and convergence of the sliding regime.

- The determination of the control law.

\subsubsection{Choice of sliding surface}

To regulate the speed, the rotor current Irq must be adjusted.

The control law is expressed with:

$i_{r q}^{r e f}=i_{r q}^{e q}+i_{r q}^{n}$ 
The speed error in our case is going to be the sliding surface which is expressed by the following law:

$S(\omega)=\omega_{\text {ref }}-\omega$

Its derivative is given by:

$\dot{S}(\omega)=\dot{\omega}_{\text {ref }}-\dot{\omega}$

By replacing equation (5) in (3) we obtain the expression of the following form:

$\dot{\omega}=-\frac{P^{2}}{J} \psi_{r d}^{r e f} i_{r q}-\frac{P}{J} T_{r}-\frac{f}{J} \omega$

Which gives:

$\dot{S}(\omega)=\dot{\omega}_{r e f}+\frac{P^{2}}{J} \psi_{r d}^{r e f} i_{r q}+\frac{P}{J} T_{r}+\frac{f}{J} \omega$

By replacing expression (18) in expression (22) we will have:

$\dot{S}(\omega)=\dot{\omega}_{r e f}+\frac{P^{2}}{J} \psi_{r d}^{r e f}\left(i_{r q}^{e q}+i_{r q}^{n}\right)+\frac{P}{J} T_{r}+\frac{f}{J} \omega$

\subsubsection{Definition of the conditions of existence and convergence of the sliding regime}

During sliding mode and steady state: $S(\omega)=0$

Therefore,

$\dot{S}(\omega)=0$ et $i_{r q}^{n}=0$

So $i_{r q}^{e q}$ is going to be of the following form:

$0=\dot{\omega}_{r e f}+\frac{P^{2}}{J} \psi_{r d}^{r e f} i_{r q}^{e q}+\frac{P}{J} T_{r}+\frac{f}{J} \omega$

As a result:

$i_{r q}^{e q}=-\frac{J}{P^{2} \psi_{r d}^{r e f}}\left(\dot{\omega}_{r e f}+\frac{P}{J} T_{r}+\frac{f}{J} \omega\right)$

During the convergence mode, the derivative of the lyapunov equation must be negative [16]:

$\dot{V}(\omega)=\dot{S}(\omega) S(\omega)<0$

If we replace (27) in (24), we get:

$\dot{S}(\omega)=\frac{P^{2}}{J} \psi_{r d}^{r e f} i_{r q}^{n}$

\subsubsection{Determination of the control law}

To satisfy Lyapunov's condition it is necessary that $i_{r q}^{n}$ must be of opposite sign to that of $s(\omega)$.

The form which meets this condition and which makes it possible to reduce or eliminate the chatter phenomenon, which is generally undesirable because it adds high frequency components to the control law is expressed, by the following form [14]:

$i_{r q}^{e q}=K_{\omega} \operatorname{sign}(S(\omega))$ 
Based on (18), (26) and (29) we can establish the Simulink model of the speed control law by SMC, which is illustrated by the following figure (7).

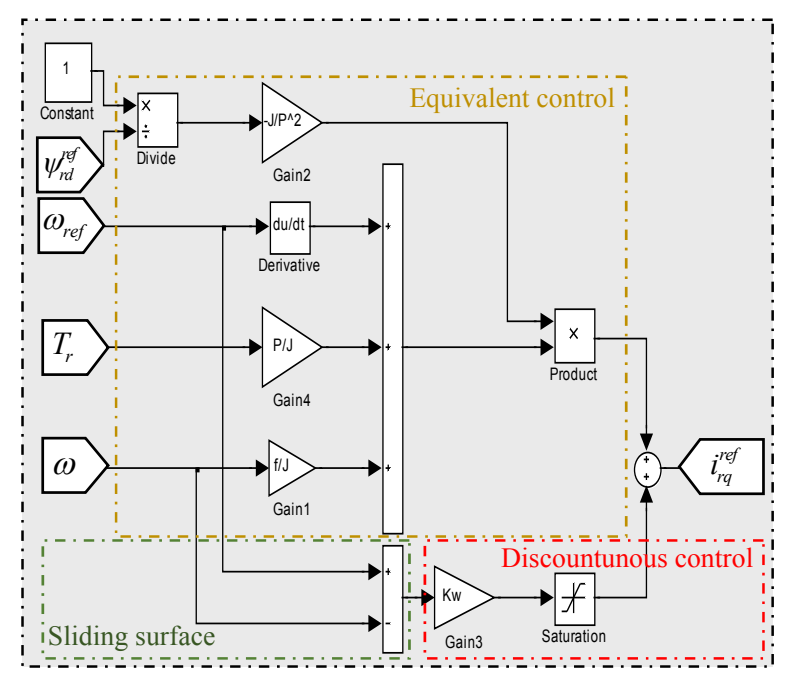

Fig. 7. Scheme of control law

\section{Simulation result and interpretation}

\subsection{Simulation procedure}

For the simulation on the Matlab/Simulink environment, we proceeded to configure the DFIM and the control with the parameters of table III and Table IV also; we applied to this system the following reference instructions:

- A trapezoidal reference speed setpoint with a maximum value of $157 \mathrm{rad} / \mathrm{s}$ and a minimum value of $-157 \mathrm{rad} / \mathrm{s}$, the choice of this setpoint is justified by the robustness test of this control in order to set it to conditions similar to the reality.

- An all-or-nothing reference torque setpoint of value $10 \mathrm{Nm}$ applied at time $t=1.8 \mathrm{~s}$, to put the DFIM under load and at no-load with a variable speed in order to test the behavior of the DFIM under the conditions cited.

After the simulation of the system on the Matlab/Simulink environment we found the following results:

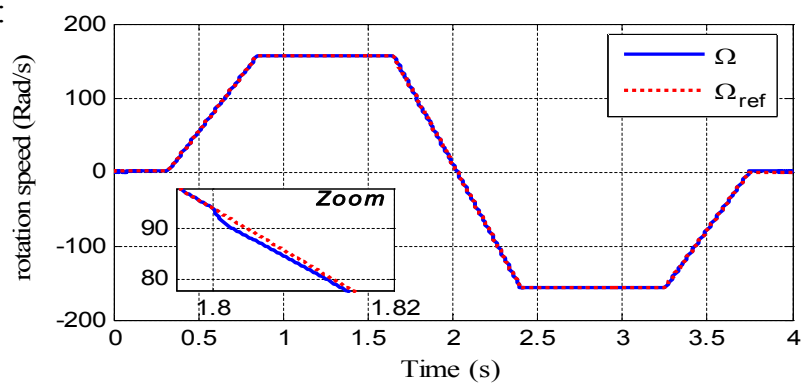

Fig. 8. Response of rotation speed 


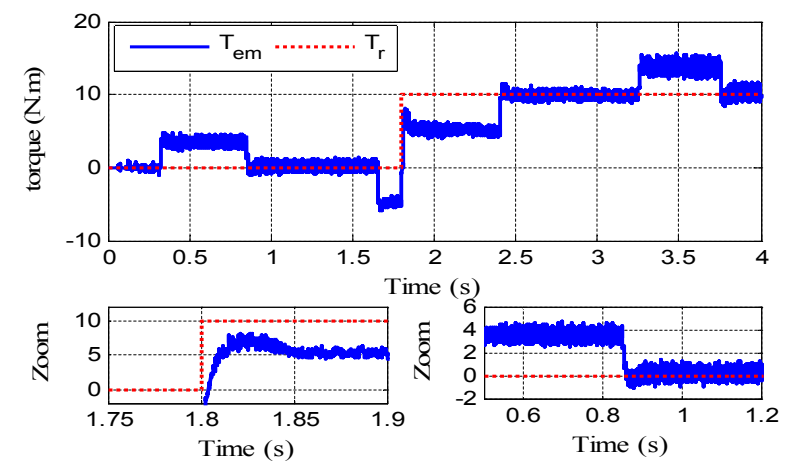

Fig. 9. Response of the electromagnetic torque
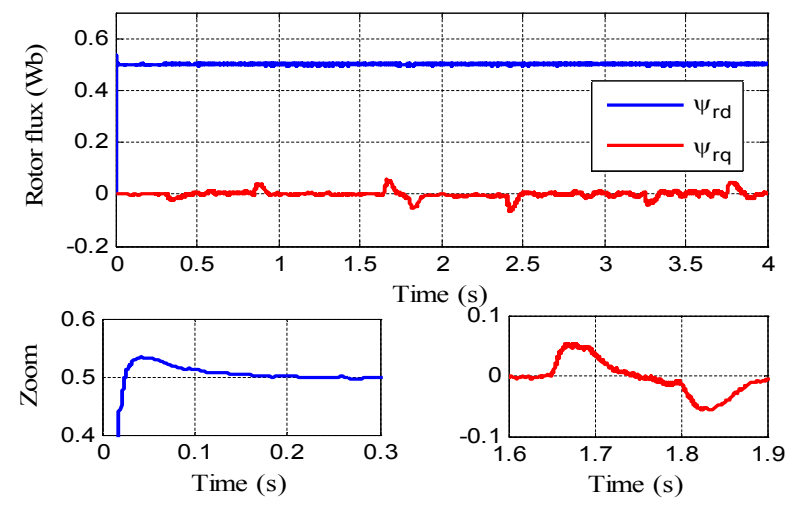

Fig. 10. Response of rotor flux
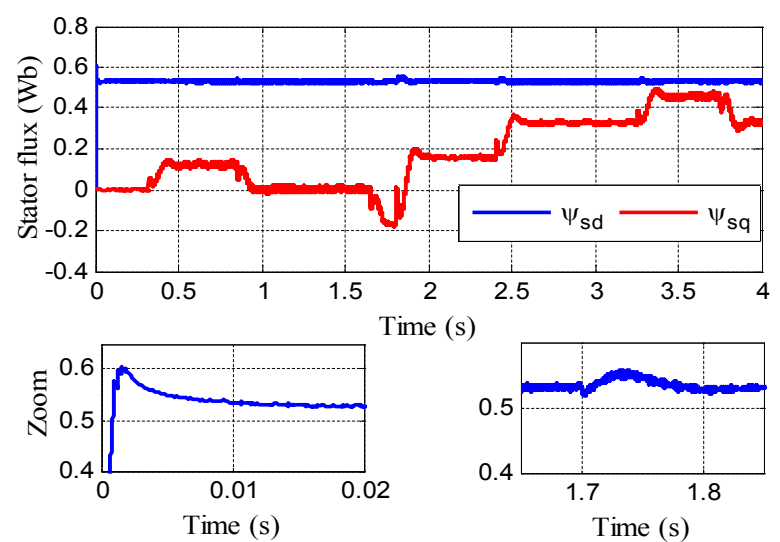

Fig. 11. Response of stator flux

\subsection{Interpretation}

The simulation results show an acceptable behaviour of the motor despite of the variation in the load.

The speed of rotation follows its reference with a low tracking error during the transient phases, and cancelling out in steady state; it presents low peaks when going from one state to another with an overshoot of $0.33 \%$. 
We also observe that the speed is sensitive to load disturbances, because there is a peak with a relative fall of $2.2 \%$ for the torque of $\mathrm{Tr}=10 \mathrm{~N}$.m. In addition, the motor torque perfectly follows its reference value, but it presents oscillations during setpoint changes.

On the other hand, these results also show that the decoupling between the electromagnetic torque and the rotor flux is very satisfactory. The direct component of the rotor flux follows almost its reference value and the quadrature component takes almost zero value imposed by the orientation condition of the rotor flux as shown in Figure (10). However, the component of the flux marks some pulses during the application of the load torque and especially when the speed is reversed.

\section{Conclusion}

This article presents a modelling of the Doubly Fed Induction Motor, with its control based on the study of RFOC with speed control by sliding mode (SMC), and the implementation of the system on the Matlab/Simulink environment.

The results of the simulation have showed an acceptable behaviour dealing with speed variations in both directions when empty and when loaded.

Speed control by sliding mode proves acceptable stability properties of the behaviour of the machine.

This approach presents ripples at the level of the torque; this is the problem to be studied in future work using robust controls based on artificial intelligence.

\section{Appendix}

TABLE II. PARAMETERS TABLE

\begin{tabular}{|c|l|}
\hline \multicolumn{1}{|c|}{ Parameters } & \multicolumn{1}{c|}{ Description } \\
\hline $\mathrm{V}_{\mathrm{sd}}, \mathrm{V}_{\mathrm{sq}}, \mathrm{V}_{\mathrm{rd}}$ and $\mathrm{V}_{\mathrm{rq}}$ & Stator and rotor voltages $(\mathrm{dq})$ \\
\hline $\mathrm{I}_{\mathrm{sd}}, \mathrm{I}_{\mathrm{sq}}, \mathrm{I}_{\mathrm{rd}}$ and $\mathrm{I}_{\mathrm{rq}}$ & Stator and rotor currents $(\mathrm{dq})$ \\
\hline$\Psi_{\mathrm{sd}}, \Psi_{\mathrm{sq}}, \Psi_{\mathrm{rd}}$ and $\Psi_{\mathrm{rq}}$ & Stator and rotor fluxes $(\mathrm{dq})$ \\
\hline $\mathrm{R}_{\mathrm{s}}, \mathrm{R}_{\mathrm{r}}$ & Stator and rotor resistors \\
\hline $\mathrm{L}_{\mathrm{s}}, \mathrm{L}_{\mathrm{r}}$ & Stator and rotor inductors \\
\hline $\mathrm{M}$ & Mutual Inductance \\
\hline $\mathrm{P}$ & Number of pairs of poles \\
\hline$\omega_{\mathrm{r}}$ & Rotor angular speed \\
\hline$\omega_{\mathrm{s}}$ & Stator angular speed \\
\hline$\Omega$ & Rotation speed \\
\hline $\mathrm{T}_{\mathrm{m}}$ & Electromagnetic torque \\
\hline $\mathrm{T}_{\mathrm{r}}$ & Resistant torque \\
\hline $\mathrm{f}$ & Viscous friction coefficient \\
\hline $\mathrm{J}$ & Moment of inertia \\
\hline$\sigma$ & Dispersion coefficient \\
\hline$\xi$ & Damping ratio \\
\hline$\omega$ & Natural frequency \\
\hline
\end{tabular}

TABLE III. ABBreVIATION TABLE

\begin{tabular}{|c|l|}
\hline Abbreviation & \multicolumn{1}{c|}{ Wording } \\
\hline DFIM & Doubly fed induction motor \\
\hline RFOC & Rotor flux oriented control \\
\hline PWM & Pulse width modulation \\
\hline SMC & Sliding mode control \\
\hline DC & Direct current \\
\hline
\end{tabular}


TABLE IV. DFIM PARAMETERS TABLE

\begin{tabular}{|c|c|}
\hline Symbols & Values (Unit) \\
\hline $\mathrm{P}_{\mathrm{n}}$ & $1.5 \mathrm{Kw}$ \\
\hline $\mathrm{Vs}$ & $230 \mathrm{v}$ \\
\hline $\mathrm{Vr}$ & $130 \mathrm{v}$ \\
\hline $\mathrm{P}$ & 2 \\
\hline $\mathrm{f}$ & $50 \mathrm{~Hz}$ \\
\hline $\mathrm{R}_{\mathrm{s}}$ & $1.75 \Omega$ \\
\hline $\mathrm{R}_{\mathrm{r}}$ & $1.68 \Omega$ \\
\hline $\mathrm{L}_{\mathrm{s}}$ & $0.295 \mathrm{H}$ \\
\hline $\mathrm{L}_{\mathrm{r}}$ & $0.104 \mathrm{H}$ \\
\hline $\mathrm{M}$ & $0.165 \mathrm{H}$ \\
\hline $\mathrm{f}$ & $0.0027 \mathrm{~kg} \cdot \mathrm{m}^{2} / \mathrm{s}$ \\
\hline $\mathrm{J}$ & $0.001 \mathrm{~kg} \cdot \mathrm{m}^{2}$ \\
\hline
\end{tabular}

TABLE V. CONTROL PARAMETERS TABLE

\begin{tabular}{|c|c|}
\hline Symbols & Values \\
\hline $\mathrm{K}_{\mathrm{is}(\mathrm{dq})}$ & 2736 \\
\hline $\mathrm{K}_{\mathrm{ps}(\mathrm{dq})}$ & 117 \\
\hline $\mathrm{K}_{\mathrm{ir}(\mathrm{dq})}$ & 965 \\
\hline $\mathrm{K}_{\mathrm{pr}(\mathrm{dq})}$ & 40 \\
\hline $\mathrm{K}_{\mathrm{i} \Psi}$ & 562 \\
\hline $\mathrm{K}_{\mathrm{p} \Psi}$ & 18 \\
\hline$\xi$ & 0.7 \\
\hline$\omega_{0}$ & 287 \\
\hline $\mathrm{t}_{\mathrm{i}}$ & $0.01 \mathrm{~s}$ \\
\hline $\mathrm{K}_{\mathrm{w}}$ & $157 \mathrm{rad} / \mathrm{s}$ \\
\hline
\end{tabular}

\section{References}

1. Vidal .P.E., David .P, \& Bonnet .F. « Mixed control strategy of a doubly fed induction machine», Electrical Engineering, 90(5), 337-346. (2007).

2. Bonnet, F., Vidal, P.-E., \& Pietrzak-David, M. «Dual Direct Torque Control of Doubly Fed Induction Machine », IEEE Transactions on Industrial Electronics, 54(5), 2482-2490,(2007).

3. F. Blaschke. "The principle of field oriented as applied to the new transvector closed-Ioop control system for rotating machines ». Siemens Review, 1972, Vo139, N4, pp217-220.

4. K. Hasse, "Zum dynamischen Verhalten der Asynchron maschine bei Betrieb mit variabler Ständerfrequenz und Ständerspannung », ETZ-A, vol. 89, p. 387-391, 1968.

5. M. Taoussi, M. Karim, B. Bossoufi, D. Hammoumi, A. Lagrioui,“ Speed Backstepping Control of The Double-Fed Induction Machine DRIVE“", Journal of Theoretical \& Applied Information Technology, Vol.74, №.02, pp. 189-199, Avril, 20, 2015.

6. El Ouanjli, N., Motahhir, S., Derouich, A., El Ghzizal, A., Chebabhi, A., \& Taoussi, M. « Improved DTC strategy of doubly fed induction motor using fuzzy logic controller ». Energy Reports, 5, 271-279. (2019).

7. Sabanovic A, Izosimov DB «Application of sliding modes to induction motor control », IEEE Trans on industry applications IA-17(1): 41-49, (1981).

8. El Ouanjli, N., Derouich, A., El Ghzizal, A. et al. «Direct torque control of doubly fed induction motor using three-level NPC inverter», Prot Control Mod Power Syst 4, 17 (2019).

9. M. Elmahfoud , B.Boussoufi , M.Taoussi , N. Elounajli, A. Derouich « Rotor Field Oriented Control of Doubly Fed Induction Motor » 978-1-7281-1482-8/19/\$31.00 C2019 IEEE, Maroc 2019. 
10. D. Lecoq, Ph. Lataire, «Study of variable speed, double fed induction motor drive with both stator and rotor volatges controllable», Conference Proceedings EPE' 91, Firenze, Vol II, pp. 337-339.

11. R. Ghosn, C. Asmar, M. Pietrzak-David, B. de Fornel, «An improved control scheme for doubly fed induction machine », EPE 2001 Conference, Graz, Austria, 27-29 August 2001.

12. D. Ramuz, M. Godfroid, A. Mirzaian, J. M. Kauffmann, S. Tnani, «Control strategy of double fed induction machine for variable speed drives », ICEM 1998, September 2-4, Istanbul Turkey, pp. 1340-1345.

13. M. Taoussi, M. Karim, B. Bossoufi, D. Hammoumi, A. Lagrioui, A. Derouich,“" Speed variable adaptive backstepping control of the doubly-fed induction machine drive", International Journal of Automation and Control, Vol.10, $\mathrm{N}^{\circ} .01$, pp. 12-33, 2016.

14. A. Larbaoui, B. Belabbes, A. Meroufel, D. Bouguenna « Commande par mode glissant floue de la machine synchrone», Rev. Roum. Sci. Techn.- Électrotechn. et Énerg.Vol. 62, 2, pp. 192196, Bucarest, 2017.

15. C.P.Coleman, D.Grodble, «A comparison of robustness fuzzy logic, PID, sliding mode control », IEEE, pp.1654-1659, 1994.

16. M. A. FNAIECH, F. BETIN, F. FNAIECH, G. A. CAPOLINO, « Sliding mode control for dual three-phase induction motor drives » IEEE ISIE, Montréal, Québec, Canada, pp. 2281-2285, July 9-12 2006. 